\title{
A filosofia da história de Walter Benjamin
}

\author{
MICHAEL LÖWX
}

$\mathrm{E}$ STAMOs habituados a classificar as diferentes filosofias da história em consonância com seu caráter progressista ou conservador, revolucionário ou nostálgico em relação ao passado. Walter Benjamin escapa a tais classificações. Trata-se de um crítico revolucionário da filosofia do progresso, um adversário marxista do "progressismo", um nostálgico do passado que sonha com o futuro.

A recepção de Benjamin, sobretudo na França, interessou-se prioritariamente pela vertente estética de sua obra, com certa propensão a considerá-lo, sobretudo, historiador da cultura ou crítico literário. Ora, sem negligenciar esse aspecto, se faz necessário evidenciar o alcance muito mais vasto de seu pensamento, o qual visa nada menos que uma nova compreensão da história humana. Os escritos sobre arte ou literatura só podem ser compreendidos em relação a essa visão de conjunto a iluminá-los de seu interior.

A filosofia da história de Walter Benjamin bebe em três fontes diferentes: o romantismo alemão, o messianismo judeu e o marxismo. Não é uma combinatória ou "síntese" dessas três perspectivas (aparentemente) incompatíveis, mas a invenção, a partir delas, de uma nova concepção, profundamente original.

A expressão "filosofia da história” pode induzir a erro. Não há, em Benjamin, um sistema filosófico: toda sua reflexão toma a forma do ensaio ou fragmento - quando não se trata da citação pura e simples, com passagens retiradas de contexto e colocadas a serviço de sua própria dinâmica. Qualquer tentativa de sistematização é, portanto, problemática e incerta. As breves notas a seguir são apenas algumas pistas de pesquisa.

$\mathrm{Na}$ literatura sobre Benjamin, deparamo-nos, freqüentemente, com dois erros simétricos, que devem ser evitados a todo custo: o primeiro consiste em dissociar, por meio de uma operação (no sentido clínico do termo) de "corte epistemológico", a obra de juventude "idealista" e teológica da "materialista" e revolucionária da maturidade; o segundo, em contrapartida, encara sua obra como um todo homogêneo e não leva absolutamente em consideração a alteração profunda trazida, por volta dos anos 20, pela descoberta do marxismo. Para compreender o movimento do seu pensamento, é preciso, pois, considerar simultaneamente a continuidade de certos temas essenciais e as diversas curvas e rupturas que pontilham sua trajetória intelectual e política. 
Poderíamos tomar como ponto de partida a conferência de 1914 sobre "A Vida dos Estudantes" que apresenta, de chofre, algumas das principais linhas de força de tal trajetória. As observações que abrem esse ensaio contêm uma amostra surpreendente de sua filosofia messiânica da história:

Confiante no infinito do tempo, certa concepção da história discerne apenas o ritmo mais ou menos rápido, segundo o qual homens e épocas avançam no caminho do progresso. Donde o caráter incoerente, impreciso, sem rigor, da exigência dirigida ao presente. Aqui, ao contrário, como sempre têm feito os pensadores, apresentando imagens utópicas, vamos considerar a história à luz de uma situação determinada que a resume em um ponto focal. Os elementos da situação final não se apresentam como tendência progressista informe, mas, a título de criações e idéias em enorme perigo, altamente desacreditadas e ridicularizadas, incorporam-se de maneira profunda a qualquer presente [...] Essa situação [...] só é apreensível na sua estrutura metafísica, como o reino messiânico ou a idéia revolucionária, no sentido de 89 (1).

Imagens utópicas - messiânicas e revolucionárias - contra a "informe tendência progressista": estão aí colocados, em resumo, os termos do debate que Benjamin realizará ao longo de toda a sua obra. Como vai se articular, mais tarde, essa primeira intuição com o materialismo histórico?

É a partir de 1924, quando lê História e consciência de classe, que o marxismo vai gradualmente se tornar um elemento-chave da concepção da história. Em 1929, Benjamin se refere ainda ao ensaio de Lukacs como um dos raros livros que permanecem vivos e atuais: "A obra mais acabada da literatura marxista. Sua singularidade se fundamenta na segurança com a qual apreendeu, de um lado a situação crítica da luta de classes na situação crítica da filosofia e, de outro, a revolução, a partir de agora concretamente madura, como a pré-condição absoluta, ou até mesmo a realização e a conclusão do conhecimento teórico" (2).

Esse texto mostra qual é o aspecto do marxismo que mais interessa a Benjamin e vai aclarar com uma luz nova sua visão do processo histórico: a luta de classes. No entanto, o materialismo histórico não vai substituir suas intuições “anti-progressistas", de inspiração romântica e messiânica; vai se articular com elas, ganhando, dessa maneira, uma qualidade crítica que o distingue radicalmente do marxismo "oficial" dominante na época.

Tal articulação se manifesta pela primeira vez no livro Sens unique, escrito entre 1923 e 1926, onde se encontra, sob o título "Avertisseur d'incendie", essa premonição histórica das ameaças do progresso: se a derrubada da burguesia pelo proletariado "não se realiza antes de um momento quase calculável da evolução técnica e científica (indicado pela inflação e pela guerra química), tudo está perdido. É preciso cortar o pavio que queima antes que a faísca atinja a dinamite" (3).

Contrariamente ao marxismo evolucionista vulgar, Benjamin não concebe a revolução como o resultado "natural" ou "inevitável” do progresso econômico 
e técnico (ou da "contradição entre forças e relações de produção"), mas como a interrupção de uma evolução histórica que conduz à catástrofe.

É porque percebe esse perigo catastrófico que Benjamin invoca o pessimismo em seu artigo de 1929 sobre o surrealismo, um pessimismo revolucionário que não tem nada a ver com a resignação fatalista e ainda menos com o Kulturpessimismus alemão, conservador, reacionário e pré-fascista (Carl Schmitt, Oswald Spengler, Moeller van der Bruck): o pessimismo aqui está a serviço da emancipação das classes oprimidas. Sua preocupação não é o "declínio" das elites ou da nação, mas as ameaças que o progresso técnico e econômico promovido pelo capitalismo faz pesar sobre a humanidade.

Nada parece mais ridículo aos olhos de Benjamin que o otimismo dos partidos burgueses e da social democracia, cujo programa político não é outra coisa que "um mau poema de primavera". Contra esse "otimismo sem consciência", esse "otimismo de diletantes", inspirado pela ideologia do progresso linear, ele descobre no pessimismo o ponto de convergência efetiva entre surrealismo e comunismo (4). É evidente que não se trata de um sentimento contemplativo, mas de um pessimismo ativo, "organizado", prático, inteiramente dedicado ao objetivo de impedir, por todos os meios possíveis, a chegada do pior.

Perguntamo-nos a que pode se referir o conceito de pessimismo aplicado aos comunistas: sua doutrina em 1928, celebrando os triunfos da construção do socialismo na URSS e a queda iminente do capitalismo, não é precisamente um belo exemplo de ilusão otimista? De fato, Benjamin tomou emprestado o conceito de "organização do pessimismo" de uma obra qualificada por ele como "excelente", La révolution et les intellectuels (1926), do comunista dissidente Pierre Naville. Próximo dos surrealistas (tinha sido um dos redatores da revista La Révolution Surréaliste), Naville fizera naquele momento a opção do engajamento político no partido comunista francês e queria dividi-la com seus amigos.

Ora, para Pierre Naville, o pessimismo, que constitui "a fonte do método revolucionário de Marx", é o único meio de "escapar às nulidades e às desventuras de uma época de compromisso". Recusando o "grosseiro otimismo" de um Herbert Spencer - a quem gratifica com o amável qualificativo de "cérebro monstruosamente diminuído" - ou de um Anatole France, cujas "infames brincadeiras" não suporta, conclui: "é preciso organizar o pessimismo", "a organização do pessimismo" é a única palavra de ordem que nos impede de enfraquecer (5).

Torna-se inútil precisar que tal apologia apaixonada do pessimismo era muito pouco representativa da cultura política do comunismo francês na época. De fato, Pierre Naville seria logo excluído (1928) do partido: a lógica de seu anti-otimismo o conduzirá às fileiras da oposição comunista de esquerda ("trotskista”), da qual se tornará um dos principais dirigentes.

A filosofia pessimista da história de Benjamin se manifesta de maneira particularmente aguda em sua visão do futuro europeu: "Pessimismo em toda a linha. Sim, na verdade, e totalmente. Desconfiança quanto ao destino da litera- 
tura, desconfiança quanto ao destino da liberdade, desconfiança quanto ao destino do homem europeu, mas sobretudo desconfiança tripla diante de qualquer acomodação: entre as classes, entre os povos, entre os indivíduos. E confiança ilimitada apenas na I. G. Farben e no aperfeiçoamento pacífico da Luftwaffe" (6).

Essa visão crítica permite a Benjamin perceber - intuitivamente, mas com uma estranha acuidade - as catástrofes que esperavam a Europa, perfeitamente resumidas na frase irônica sobre a "confiança ilimitada". Evidentemente, mesmo ele, o mais pessimista de todos, não podia prever as destruições que a Luftwaffe iria infligir às cidades e populações civis européias; e ainda menos imaginar que a I. G. Farben , passados apenas 12 anos, se destacaria pela fabricação do gás Ziklon B utilizado para "racionalizar" o genocídio, e que suas fábricas empregariam, na casa das centenas de milhares, a mão-de-obra de prisioneiros de campos de concentração. Entretanto, único entre os pensadores e dirigentes marxistas daqueles anos, Benjamin teve a premonição dos monstruosos desastres que podia engendrar a civilização industrial/burguesa em crise.

É sobretudo no Livro das passagens parisienses e nos diferentes textos dos anos 1936-40 que Benjamin vai desenvolver sua visão da história, dissociando-se, de modo mais ou menos radical, das "ilusões de progresso" hegemônicas no seio do pensamento de esquerda alemã e européia. Em um artigo publicado em 1937 na célebre Zeitschrift für Sozialforschung, a revista da Escola de Frankfurt (já exilada nos Estados Unidos), dedicado ao historiador e colecionador Eduard Fuchs, ele ataca o marxismo social democrata, mistura de positivismo, evolucionismo darwinista e culto do progresso: "Ele não podia ver na evolução da técnica outra coisa a não ser o progresso das ciências naturais e não a regressão social [...]. As energias que a técnica desenvolve para além desse limite são destrutivas. Colocam em primeira linha a técnica da guerra e sua preparação pela imprensa" (7).

O objetivo de Benjamin é aprofundar e radicalizar a oposição entre o marxismo e as filosofias burguesas da história, aguçar seu potencial revolucionário e elevar-lhe o conteúdo crítico. É nesse espírito que define, de maneira decisiva, a ambição do projeto das Passagens parisienses: "Podemos considerar também como finalidade seguida metodologicamente neste trabalho a possibilidade de um materialismo histórico que tenha aniquilado (annibiliert) em si mesmo a idéia de progresso. É justamente se opondo aos hábitos do pensamento burguês que o materialismo histórico encontra suas fontes" (8). Tal programa não implicava qualquer "revisionismo", mas, ao contrário, como Karl Korsch tentara fazer em seu próprio livro - uma das principais referências de Benjamin - um retorno ao próprio Marx.

Benjamin estava consciente de que essa leitura do marxismo mergulhava suas raízes na crítica romântica da civilização industrial, mas estava convencido de que Marx também tinha se inspirado nessa fonte. Encontra um apoio para tal interpretação heterodoxa das origens do marxismo em Karl Marx (1938) de Korsch: "De modo muito acertado e não sem nos fazer pensar em Maistre e 
Bonald, Korsch diz o seguinte: 'Assim, na teoria do movimento operário moderno, também, há uma parte da "desilusão" que, depois da grande Revolução francesa, foi proclamada pelos primeiros teóricos da contra-revolução e, em seguida, pelos românticos alemães e que, graças a Hegel, teve forte influência sobre $\operatorname{Marx} "$ " (9).

A formulação mais espantosa e radical da nova filosofia da história - marxista e messiânica - de Walter Benjamin se encontra, indubitavelmente, nas Thèses sur le concept d'histoire, de 1940, um dos documentos mais importantes do pensamento revolucionário desde as Teses sobre Feuerbach, de 1845.

A exigência fundamental de Benjamin é escrever a história a contrapelo, ou seja, do ponto de vista dos vencidos - contra a tradição conformista do historicismo alemão cujos partidários entram sempre "em empatia com o vencedor" - Tese VII (10).

É evidente que a palavra "vencedor" não faz referência a batalhas ou guerras habituais, mas à "guerra de classes", na qual um dos campos, a classe dirigente, "não cessou de vencer" (Tese VII) os oprimidos - desde Spartacus, o gladiador rebelde, até o grupo Spartacus de Rosa de Luxemburgo, e desde o Imperium romano até o Tertium Imperium nazista.

O historicismo se identifica enfaticamente (Einfüblung) com as classes dominantes. Ele vê a história como uma sucessão gloriosa de altos fatos políticos e militares. Fazendo o elogio dos dirigentes e prestando-lhes homenagem, confere-lhes o estatuto de "herdeiros" da história passada. Em outros termos, participa - como essas pessoas que levantam a coroa de louros acima da cabeça do vencedor - de um "cortejo triunfal em que os senhores de hoje caminham por sobre o corpo dos vencidos” (Tese VII).

A crítica que Benjamin formula contra o historicismo se inspira na filosofia marxista da história, mas tem também origem nietzschiana. Em uma obra de juventude, Da utilidade e da inconveniência da história (citada na Tese XII), Nietzsche ridiculariza a "admiração nua pelo sucesso" dos historicistas, sua "idolatria do factual" (Götzerdienste des Tatsächlichen) e a tendência a se inclinarem diante da "pujança da história". Já que o Diabo é o senhor do sucesso e do progresso, a verdadeira virtude consiste em insurgir-se contra a tirania da realidade e nadar contra a corrente histórica.

Existe uma ligação evidente entre esse panfleto de Nietzsche e a exortação de Benjamin para escrever a história gegen den Strich. No entanto, as diferenças não são menos importantes: enquanto a crítica nietzschiana ao historicismo se faz em nome da "Vida" ou do "Indivíduo heróico", a de Benjamin fala em nome dos vencidos. Na sua condição de marxista, ele se situa no lado oposto ao elitismo aristocrático de Nietzsche e escolhe identificar-se com os "danados da Terra", os que jazem sob as rodas desses carros majestosos e magníficos chamados Civilização ou Progresso. 


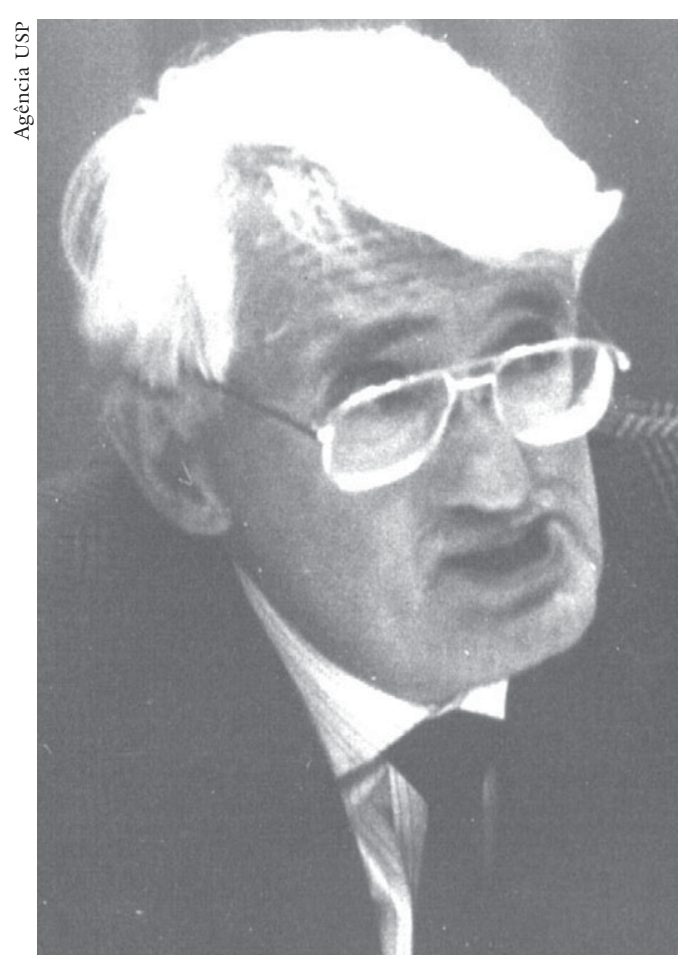

Jürgen Habermas

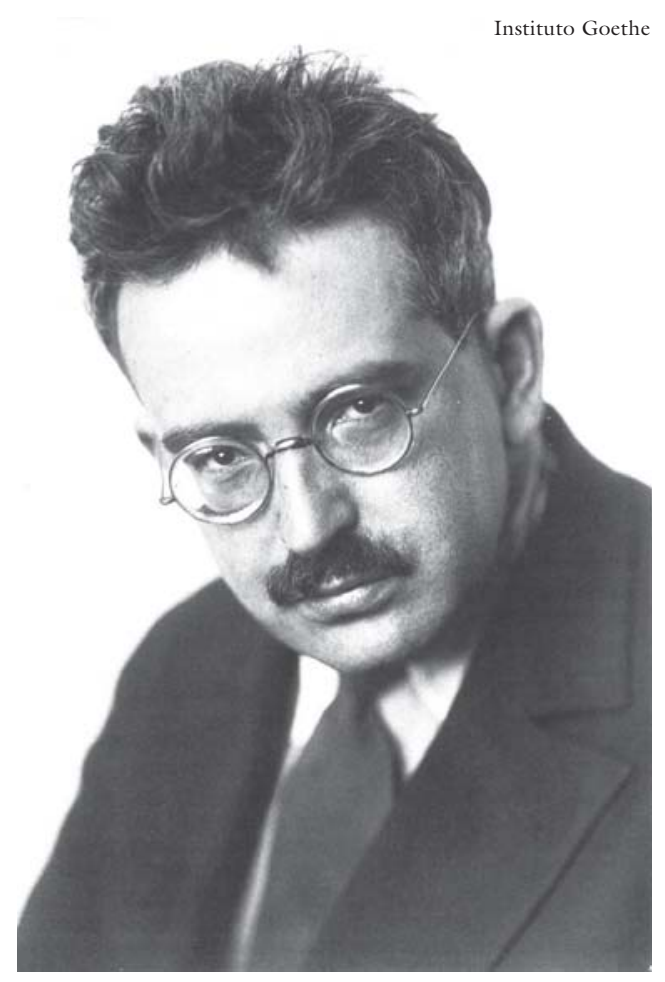

Walter Benjamin

Rejeitando o culto moderno da Deusa Progresso, Benjamin coloca no centro de sua filosofia da história o conceito de catástrofe. Em uma das notas preparatórias às Teses de 1940, observa: "A catástrofe é o progresso, o progresso é a catástrofe. A catástrofe é o contínuo da história" (11). A assimilação de progresso e catástrofe tem, antes de mais nada, uma significação histórica: do ponto de vista dos vencidos, o passado não é senão uma série interminável de derrotas catastróficas. A revolta dos escravos, a guerra dos camponeses, junho de 1848, a Comuna de Paris e o levante berlinense de janeiro de 1919 são exemplos que aparecem freqüentemente nos escritos de Benjamin, para quem "esse inimigo não parou de vencer" (Tese VI). Essa equação, no entanto, tem também uma significação eminentemente atual, porque, "nesta hora, o inimigo ainda não parou de triunfar" (Tese VI, tradução para o francês do próprio Benjamin): a derrota da Espanha republicana, o pacto Molotov-Ribbentrop, a vitoriosa invasão nazista na Europa.

O fascismo ocupa, evidentemente, um lugar central na reflexão histórica de Benjamin nas Teses. Para ele, não é um acidente da história, um "estado de exceção", qualquer coisa impossível no século XX, um absurdo do ponto de vista do progresso: rejeitando tal tipo de ilusão, Benjamin reclama "uma teoria da história a partir da qual o fascismo possa ser percebido" (12), ou seja, uma teoria que compreenda que as irracionalidades do fascismo são apenas o avesso da racionalidade instrumental moderna. $\mathrm{O}$ fascismo leva às últimas conseqüências a combinação tipicamente moderna de progresso técnico e regressão social. 
Enquanto Marx e Engels tinham tido, segundo Benjamin, “a intuição fulgurante" da barbárie por vir, em seu prognóstico sobre a evolução do capitalismo (13), seus epígonos do século XX foram incapazes de compreender uma barbárie moderna e, portanto, de resistir eficazmente a ela - barbárie industrial, dinâmica, instalada no coração mesmo do progresso técnico e científico.

Procurando as raízes, os fundamentos metodológicos de tal incompreensão catastrófica, que contribuiu para a derrota do movimento operário alemão em 1913, Benjamin ataca a ideologia do progresso em todos os seus componentes: o evolucionismo darwinista, o determinismo de tipo científico-natural, o otimismo cego - dogma da vitória "inevitável" do partido - e a convicção de "nadar no sentido da corrente" (o desenvolvimento técnico). Em uma palavra, a crença confortável em um progresso automático, contínuo, infinito, fundado na acumulação quantitativa, no desenvolvimento das forças produtivas e no crescimento da dominação sobre a natureza. Ele crê descobrir por detrás de tais manifestações múltiplas um fio condutor que submete a uma crítica radical: a concepção homogênea, vazia e mecânica (como um movimento de relojoaria) do tempo histórico.

Contra essa visão linear e quantitativa, Benjamin opõe uma percepção qualitativa da temporalidade, fundada, de um lado, na rememoração, de outro na ruptura messiânica/revolucionária da continuidade. A revolução é o "correspondente" (no sentido baudelairiano da palavra) profano da interrupção messiânica da história, da parada messiânica do devir"(Tese XVII): as classes revolucionárias, escreve na Tese XV, estão conscientes, no momento da ação, de "romper o contínuo da história”. A interrupção revolucionária é, portanto, a resposta de Benjamin às ameaças que faz pesar sobre a espécie humana a perseguição da tempestade maléfica chamada "Progresso", uma tempestade que acumula ruínas e prepara catástrofes novas (Tese XII). Corria o ano 1940, um pouco antes de Auschwitz e Hiroshima...

Para Habermas, existe uma contradição entre a filosofia da história de Benjamin e o materialismo histórico. O erro de Benjamin foi, segundo ele, ter querido impor - "como um capuz de monge sobre a cabeça" - ao materialismo histórico de Marx, "que leva em conta progressos não somente no campo das forças produtivas, mas também da dominação", "uma concepção histórica antievolucionista" (14).

$\mathrm{Na}$ realidade, uma interpretação dialética e não evolucionista da história, levando em conta ao mesmo tempo os progressos e as regressões - como fizeram Benjamin e seus amigos da Escola de Frankfurt - pode fundamentar-se em vários escritos de Marx. No entanto, é verdade que ela entra em conflito com as interpretações dominantes do materialismo histórico, desenvolvidas no curso do século XX. O que Habermas pensa ser um erro é precisamente a fonte do valor singular da filosofia benjaminiana da história e sua capacidade de compreender um século caracterizado pela imbricação estreita entre a modernidade e a barbárie. 


\section{Notas}

1 Benjamin, W. "La Vie des Étudiantes" (1915), em Mythe et violence (Paris: Lettres Nouvelles, 1971), p. 37.

2

Gesammelte Schriften (Frankfurt: Suhrkamp Verlag, 1980), III, p. 171.

3

4 Sens unique (Paris: Lettres Nouvelles/Maurice Nadeau, 1978), pp. 205-6. Mythe et violence, p. 312

5 Naville, Pierre, La révolution et les intellectuels (Paris: Gallimard, 1965), pp. 76-7, 110-17.

6 Benjamin, W., "Le Surréalisme”, p. 312.

7 Gesammelte Schriften, III, p. 474.

8 "Passagenwerk" em Gesammelte Schriften, V, p. 574.

9 Ibid., p. 820.

10 As citações das "Thèses sur la Philosophie de l'Histoire" foram, na maioria das vezes, tiradas da tradução de Maurice de Gandillac em Poésie et révolution (Paris: Lettres Nouvelles, 1971).

11 Benjamin, W. Gesammelte Schriften, I, 3, p. 1244 (notas preparatórias para as Teses). 12 Gesammelte Schriften, I, 3, p. 1244 (notas preparatórias).

13 Gesammelte Schriften, II, 2, p. 488.

14 Habermas, J. "L’actualité de W. Benjamin. La critique: Prise de Conscience ou Préservation", Revue d'Esthétique n 1, p. 121, (1981).

Michael Löwy estudou Ciências Sociais na Universidade de São Paulo (USP) e doutorou-se na Sorbonne sob orientação de Lucien Goldmann. Vive em Paris desde 1969 e é autor de vários livros, dentre eles, La théorie de la révolution chez le jeune Marx (Maspero); Método dialético e teoria politica (Paz e Terra); Para uma sociologia dos intelectuais revolucionários (Ciências Humanas); Ideologias e ciência social (Cortez); As aventuras de Karl Marx contra o barão de Münchbausen (Busca Vida).

Tradução de Gilberto P. Passos. O original em francês - La philosophie de l'histoire de Walter Benjamin - encontra-se à disposição do leitor no IEA-USP para eventual consulta.

Palestra feita pelo autor em 28 de janeiro de 2002 na sede do Instituto de Estudos Avançados da USP. 